\title{
The Impact of Optimizing Trim on Reducing Fuel
}

\section{Consumption}

\author{
Ahmed Helmy Abouelfadl and Essam Eldin Youssef Abdelraouf \\ Upgrading Studies Institute, Arab Academy for Science, Technology and Maritime Transport (AAST\&MT), Alexandria, Egypt
}

\begin{abstract}
The shipping industry is one of the biggest industries throughout the ages. Maritime transport plays a vital role in world economy; whereas competition between maritime companies is fierce [1], at the same time agreements of co-operation have taken different forms including alliances and mergers between companies to increase their market share. But competitions still stand despite all alliances even in same market. This intense competition drives companies to attain high level of competitiveness, by monitoring ship's operating performance and operating cost, emphasis on improving performance and reduce cost. On other hand new environmental regulations come to light, expansion of ECA (emission control areas), which lead to significant higher fuel cost when using low sulfur fuel. Since the fuel cost is the largest portion of the operating cost of the vessel, a saving in fuel usage can result in considerable saving in operational costs. Furthermore, fuel saving has environmental benefits in the reduction of greenhouse gas emissions. The aim of this paper is to investigate the role of trim optimization which considers one of the easiest and cheapest methods for ship performance optimization and fuel consumption reduction trim optimization.
\end{abstract}

Key words: Shipping lines competitions, ship operating performance, emission control areas, and trim optimization.

\section{Introduction}

Since the Great economic depression, rising bunker prices and more stringent environmental regulations ship-owners are forced to keep their ships as efficiently as possible. Adding to that the result is prescribed by the IMO to reduce and regulate shipping's GHG (green house gases) emissions and global $\mathrm{CO}_{2}$ emissions. The IMO adopted legally binding for energy efficiency measures on different stages technically and operationally. Foremost amongst these technical measures, nearly all new builds have to conform to the limits of the EEDI (energy efficiency design index), which provides a method for establishing the minimum efficiency of new ships depending on the type of ship and size. It offers a fair basis for comparison and should stimulate the development of more efficient ship design [2].

SEEMP (ship energy efficiency management plan) as operational measure establishes a mechanism to

Corresponding author: Ahmed Helmy Abouelfadl, M.Sc., research fields: ship stability and operations improve the energy efficiency of ship's operation and to provide an approach for shipping companies to manage ship and fleet efficiency performance over time using [3], and the EEOI (ship energy efficiency operational index) as monitoring tool, enables operators to measure the fuel efficiency of a ship in operation and to gauge the effect of any changes in operation [3], which directly affect the fuel consumption for optimized and environmentally friendly ship operations.

This can be done by a variety of measures; many methods have been created to raise the fuel efficiency of vessels. Some are done during the design phase when the hull of vessels and the propulsion systems are improved. Others focus on energy efficiency by simulating the energy system for potential improvements, or modifications to the ships and their propulsion systems as possible solution, for older ships, especially container ships, are in first line built for speed, while some concentrate on the operational optimization of vessels on most notably the "slow steaming", or finding the optimal route. Though, 
during a typical cruise, the captain of the ship must meet predefined schedules which limit the scope for speed optimizations.

A relatively low-cost alternative to save fuel is trim optimization. One of the easiest and cheapest methods for ship performance optimization and fuel consumption reduction, does not require any hull shape modification or engine upgrade. The optimization can be done by proper ballasting or choosing of proper loading plan. By using the hydrodynamic data of the vessel and depending on someinfluences such as displacement, velocity and depth, the optimal trim can be calculated. A trim optimization, up to $5 \%$ higher fuel efficiency is achieved [4].

Trim optimization tests can provide substantial savings and a return on investment between one and six months, depending on vessel type, operation and number of vessels in the series [5]. Also the influence of water depth on possible gains has also been described.

\section{The Sample Theory of Trim Optimization}

Trim is defined as the difference between the draughts aft $\left(\mathrm{dr}_{\mathrm{A}}\right)$ and forward $\left(\mathrm{dr}_{\mathrm{F}}\right) ; \operatorname{trim}=\mathrm{dr}_{\mathrm{A}}-\mathrm{dr}_{\mathrm{F}}$, this results in positive trim to the aft. Furthermore when a vessel is trimmed, the displacement and speed are kept constant, i.e. no extra ballast is added and the power consumption varies if the resistance is changed when trimmed. The trim optimization objective is to minimize the required power at vessel specific displacement and specific speed.

The physical effects that reduce the propulsive power $\left(\mathrm{P}_{\mathrm{D}}\right)$ when a ship is trimmed can relate primarily to the hull resistance $\left(\mathrm{R}_{\mathrm{T}}\right)$ and to the total propulsive efficiency $\left(\eta_{D}\right)$ as shown in the formula below:

$$
P_{D}=\frac{R_{T} \cdot v}{\eta_{D}}[6]
$$

The ship speed (V) is from definition kept constant, so it is obvious that the aim is to reduce the resistance and/or increase the total efficiency in order to gain from trimming [6].
Simply saying, the optimum trim is the trim angle at a given condition (displacement and speed) where the required propulsion power is lower than any other trim angle at that condition. A trim optimization study seeks to find the optimum trim angles by investigating a range of normal operating conditions for a particular ship or class of ships. These investigations usually include four different ships' conditions with different displacements and four to five trim angles per displacement at four to five speeds. The results are used to develop a map over the desired range of operating trims and displacements in order to provide the ship-owners with the information necessary to ensure that the ship is always trimmed to the optimum angle and thus operating trim optimized.

\section{Optimum Trim}

All large commercial vessels are designed from first stage to perform optimally at a certain speed/speed range and draft. These are the design parameters under which the vessel was initially constructed.

Optimal trim has been explored using tank testing - the results of which are compiled into a static trim chart or table, which displays values for the optimum trim for a reasonable number of speeds and drafts and pre-defined parameters. However, this method, does not take into account the effects of the real-time variable conditions at sea. Generally, the static trim model focuses on the bow to allocate the best angle to operate the vessel, and does not take account of the height of the stern which would be a better indicator of propulsion efficiency.

The accuracy of static trim measurements is improved by sea/speed trials run by shipyards, but these only cover the relatively small variation in environmental conditions that the vessels are exposed to during testing.

In summary, static trimming (measured when a vessel is not moving) works with a given set of pre-calculated figures based on a number of variables.

When dealing with prevailing conditions that 
operate outside these parameters, optimum trimming cannot be supported (Fig. 1).

\section{Optimum Dynamic Trim vs. Static}

Most vessels however, frequently operate outside the original design parameters due to differing loading conditions, routes and itineraries. To optimize the performance of the vessel when it is operating outside the design parameters, or within them, one needs to know the optimum dynamic trim (measured when a vessel is out at sea). For any given vessel, a lack of accurate information regarding the actual trim when at sea, including displacement, water depth and speed makes it challenging to find the optimum dynamic trim. In short, there are many interrelated variables to consider when modeling the optimum dynamic trim.

It means that the trim angle at any particular displacement and speed where the propulsion power used is lower than the propulsion power used for any other trim angle at the same displacement and speed.

Operating the vessel at its optimum dynamic trim can result in the vessel sailing at a higher speed and/or lower propelling power. This translates to savings in fuel as well as other economic and environmental benefits.

\section{Hull Shape Development}

As the average ship size is growing and more modernized hull designs (i.e. especially bow and stern designs) come into play, vessels have become more sensitive to trim, with the optimum trim range becoming narrower. Ensuring that trim can be measured accurately becomes even more crucial to create maximum fuel efficiency as the vessel should know the exact trim to keep it within the narrow optimum trim range. An effective bulbous bow modifies the way the water flows around the hull, reducing drag and thus increasing speed, range, fuel efficiency and stability (Fig. 2).

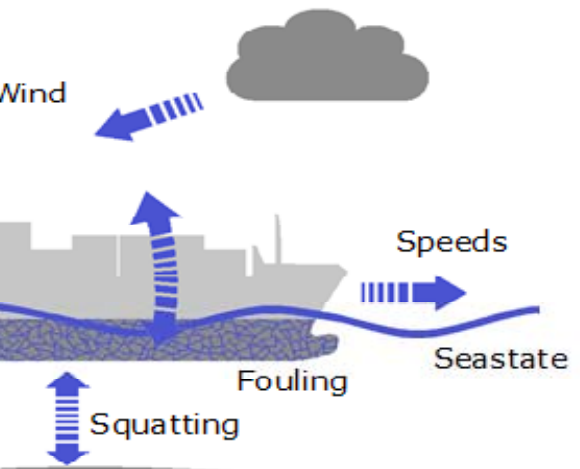

Fig. 1 The factors influencing a vessel's trim.

Source: Enimar energy management technology, dynamic vs. static trimming [8].
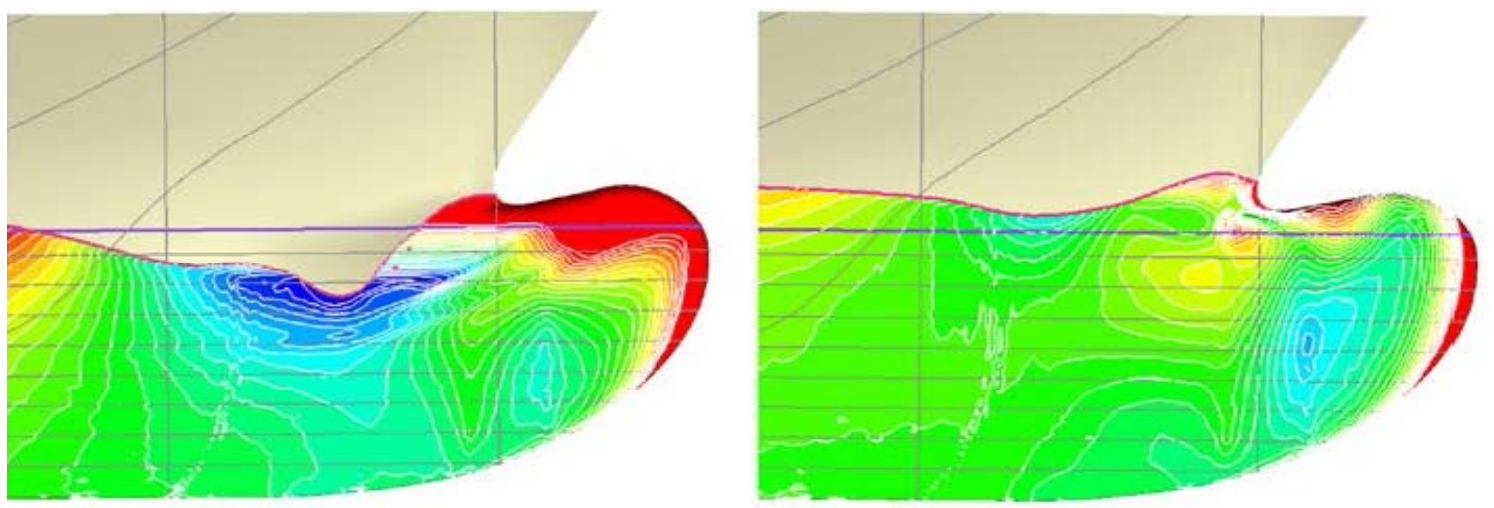

Fig. 2 Bulbous bow modifies the flow of water around the hull [19].

Source: ECO ASSISTANT 4 by DNV-GL. 
Large ships with bulbous bows generally have better fuel efficiency than similar vessels without them.

Bulbous bows have been found to be most effective when used in vessels that meet the following conditions:

- It is assumed the vessel will operate most of its time at or near its designed cruising speed;

- The bulbous bow is at the precise depth below the water line.

Large vessels that sail most of the time near their design speed will benefit from a bulbous bow. This would include cargo vessels, passenger vessels, container vessels, tankers and bulkers.

\section{Trim Optimization Practical Implementation}

Today many ship owners/operators are still using static trim tables as the predominant method of obtaining values for optimal trim. These static trim tables are prepared for the vessel in simulated conditions and are usually calculated based on 2 or 3 variables, for example draft, speed etc. They are not able to reflect the dynamic external factors that affect a vessel at sea, such as weather, currents, wave-making, etc.

A more accurate way of calculating trim is to monitor vessel performance data in real-time while taking account of the effect of dynamic conditions such as wind, and sea state. This delivers a greater accuracy and insight into how the vessel is performing and how this affects propulsion power and related fuel consumption. Knowing the optimum dynamic trim, means knowing what angle to the waterline the vessel should operate at in order to consume the least amount of fuel. Using less fuel means lower bunker bills and $\mathrm{CO}_{2}$ (carbon dioxide) emissions.

\section{Real Time Dynamic Trim Optimizer}

The aim of the using real time dynamic trim and energy optimizer is to help the crew to sail their vessel at optimum trim for the current operating condition.
The influence of trim on fuel consumption is known for quite some time.

Continuous data collection, filtering and analysis are used to constantly improve the accuracy of the optimum trim. By collecting large amounts of data from various factors affecting the energy usage of the vessels, it is also possible to monitor the power decomposition of a vessel. This can help an operator's staff, onboard and onshore, to further pinpoint potential areas for improvement in other areas and to make fleet-wide performance comparisons.

In summary, dynamic trimming provides highly accurate trimming advice based on the collection and analysis of exact real-time data on a vessel's trim performance. Operating at optimal trim using less power and fuel can also contribute to condition-based maintenance improvements and prolonged machine life.

All that push developers in energy management technology companies which work in shipping industry to reduce fuel consumption and emissions by presenting and developing products enable vessel operators to optimize fuel consumption by maximizing the energy efficiency of their vessel or fleet. The results are minimized harmful emissions and reduced costs.

\section{Case Study}

Every shipping operator's onshore management team needs access to real-time information from each vessel in the fleet in order to be able to make informed decisions related to energy efficiency. Figs. $3 \mathrm{a}$ and $3 \mathrm{~b}$ show a comprehensive energy management web application that inspires employees to focus on efficiency. It is the ideal platform for visualizing fleet data, and facilitating collaboration between ship and shore. By collecting operational data from onboard and storage server online solutions, it processes the information and delivers the results in the form of interactive reports. These include fleet performance indicators for speed, actual/optimal trim, fuel consumption, propulsion, emissions, SEEMP measures, 


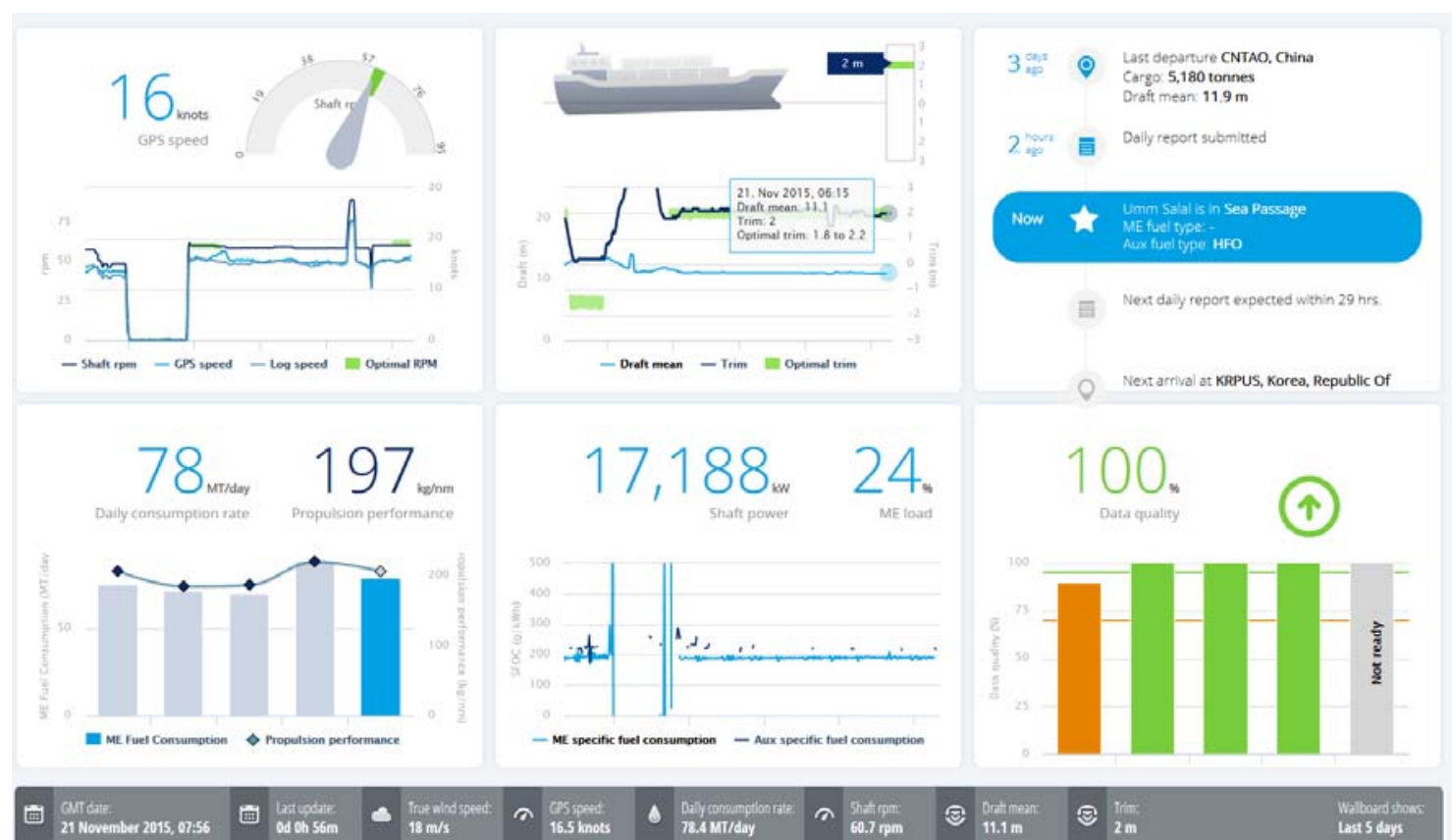

Fig. 3a Total ship monitor system “trim optimizer and fuel consumption” using Marorka energy management solutions [9]. Source: Marorka energy management solutions.
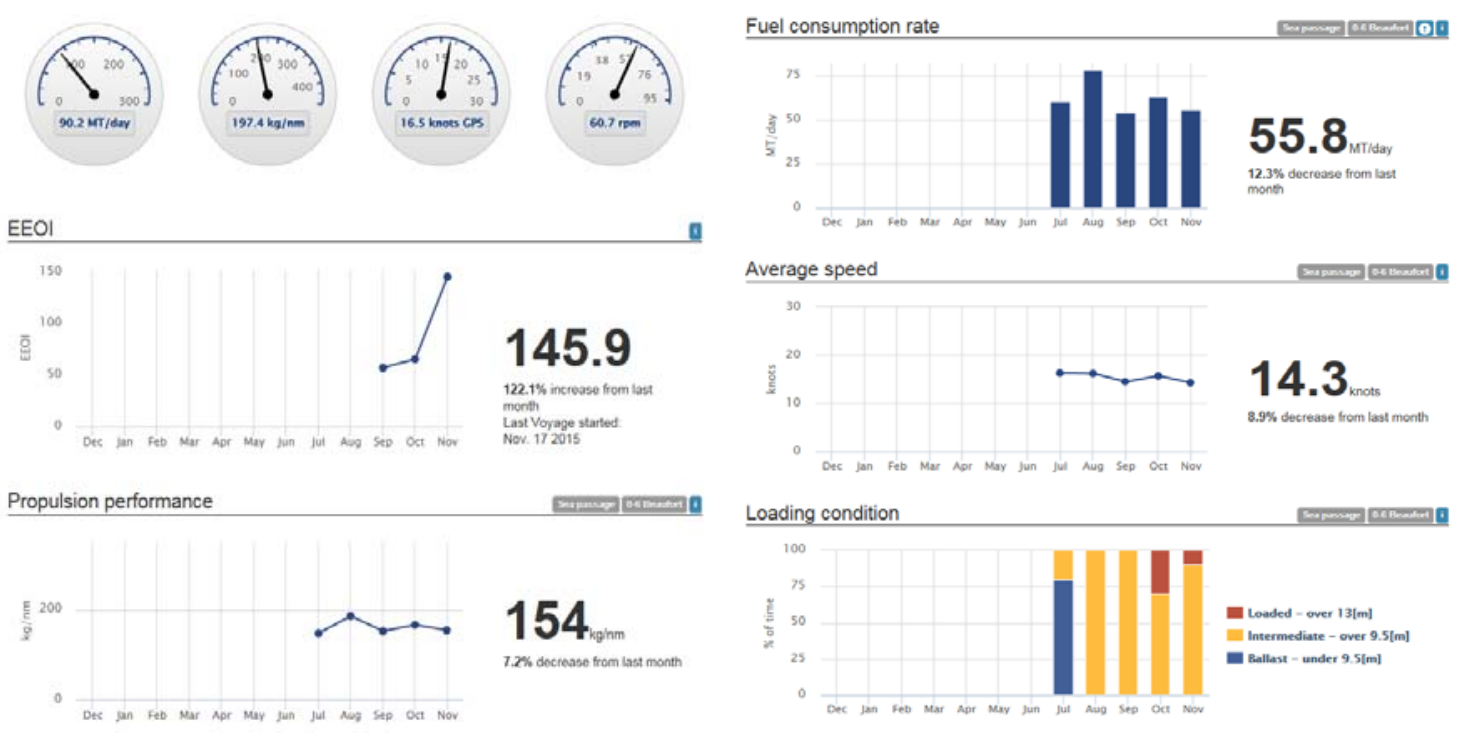

Fig. 3b Total ship monitor system “trim optimizer and fuel consumption” using Marorka energy management solutions [9]. Source: Marorka energy management solutions.

EEOI rolling average and loading condition. It provides a clear picture of a fleet's performance using live data feeds. Onshore personnel can define goals, track performance, compare ships and monitor energy efficiency in an intuitive browser environment. The system on board the ship records metered readings and makes additional calculations using a mathematical model specified for the ship's operations. These data are transmitted to online application at 15-minute intervals. The capability to continuously monitor the energy efficiency of an entire fleet allows managers to provide crews with additional support in making energy efficient decisions (Figs. 3a and 3b) [9].

\section{Conclusion}

High fuel prices and environmental concerns are 
compelling shipping companies to consider how the fuel efficiency of vessels can be improved in order to reduce cost. Since the fuel cost is by far the largest portion of the operating cost of a vessel, a fractional savings in fuel usage can result in considerable savings in operational costs. Furthermore, fuel savings have environmental benefits in the reduction of greenhouse gas emissions and $\mathrm{CO}_{2}$.

There is a direct relation between fuel consumption and ship trim, vessel operator focuses on minimize fuel consumption by optimizing the vessel trim up to $5 \%$ in annual fuel costs $[7,8]$.

Dynamic trim optimizer is an assistance tool which can provide valuable information to achieve that. Efficiency can be increased by $8.7 \%$ through sailing with the optimum trim instead of level trim. For other operating conditions the savings potential can be even higher based on many factors, such as vessel hull shape, displacement, mean draft, speed, route and depth [5].

\section{References}

[1] Kanafani, A. 2006. Global Competition in Transportation Markets Analysis and Policy Making. 1st ed. JAI Press.

[2] The Royal Institution of Naval Architects. 2014. http://www.rina.org.uk/ship_eedi.

[3] IMO [International Maritime Organization]. 2016. "Energy Efficiency Measures." http://www.imo.org/en/OurWork/Environment/Pollution Prevention/AirPollution/Pages/Technical-and-Operationa 1-Measures.aspx.

[4] Bertram, V. 2000. Practical Ship Hydrodynamics. 1st ed. Butterworth-Heinemann.

[5] Hansen, Heikki Future Ship GmbH, Potsdam/Germany and Malte Freund, Germanischer Lloyd AG, Hamburg/Germany. 2010. "Assistance Tools for Operational Fuel Efficiency." In 9th Conf. Computer and IT Applications in the Maritime Industries (COMPIT), Gubbio.
[6] Reichel, M., Minchev, A., \& Larsen, N. L. 2014. Trim Optimization-Theory and Practice. Lyngby, Denmark.

[7] Petursson, S. 2009. "Predicting Optimal Trim Configuration of Marine Vessel with Respects to Fuel Usage." Faculty of Industrial Engineering, Mechanical Engineering and Computer Science, School of Engineering and Natural Sciences, University of Iceland.

[8] Enimar Energy Management Technology. 2015. "Dynamic vs. Static Trimming." http://www.eniram.fi/about/resources/.

[9] Marorka Energy Management Solutions. 2015. http://www.marorka.com/

[10] Ballou, P., Chen, H., and Horner, J. D. 2008. "Advanced Methods of Optimizing Ship Operations to Reduce Emissions Detrimental to Climate Change." Jeppesen Commercial Marine Operations.

[11] Górski, W., Teresa A.-G., and Burciu, Z. 2013. "The Influence of Ship Operational Parameters on Fuel Consumption." Ship Design and Research Centre, Gdynia Maritime University, Gdynia, Morska.

[12] Slotte, A. 2012. "Potential Fuel Savings from Operational Measures in Sea Transport, a Study on General Environmental Improvements and Specifically on Fuel Management."

[13] Enimar Energy Management Technology. 2015. "How Real-Time Dynamic Trimming Saves More Fuel than Static Trimming." http://www.eniram.fi/about/resources.

[14] Boytim, M. 2009. Trim Optimisation-Sustainable Savings.

[15] Jan O. de Kat. 2014. "Improving the Fuel Efficiency of New \& Existing Vessels Design \& Operational Measures.” Director of Energy Efficiency \& Vessel Performance, ABS, Athena.

[16] Larsen, N. L., Simonsen, C. D., Nielsen, C. K., and Holm, C. R. 2011. FORCE Technology, Denmark, Understanding the Physics of Trim.

[17] Hochkirch, K., and Bertram, V. 2011. FutureShip GmbH.

[18] ABS SHIP ENERGY EFFICIENCY MEASURES Advisory. 2013. "Ship Energy Efficiency Measures." http://www.eagle.org/content/dam/eagle/publications/201 3/Energy\%20Efficiency.pdf.

[19] http://www.dnvgl-source.com/assets/documents/src/eco assistant_2014_01_web.pdf. 